\title{
Cloning, sequencing and transcriptional studies of the genes for cytochrome c-553 and plastocyanin from Anabaena sp. PCC 7120
}

\author{
Majid Ghassemian, ${ }^{1}$ Bess Wong, ${ }^{1}$ Fernando Ferreira, ${ }^{1}$ John L. Markley ${ }^{2}$ \\ and Neil A. Straus ${ }^{1}$
}

Author for correspondence: Neil A. Straus. Tel: +1416978 3532. Fax: +1 4169785878

e-mail: straus@botany.utoronto.ca

\footnotetext{
1 Department of Botany, University of Toronto, Toronto, Ontario, Canada M5S 3B2

2 Department of Biochemistry, College of Agriculture and Life Sciences, 420 Henry Mall, University of Wisconsin Madison, Madison, Wisconsin 53706, USA
}

\begin{abstract}
In some cyanobacteria and eukaryotic algae, cytochrome c-553 (c-552) and plastocyanin function as alternative electron carriers between the cytochrome $b_{6}-f$ complex and Photosystem I. In these organisms plastocyanin is the electron carrier under copper-replete conditions, and cytochrome c-553 is the electron carrier during copper deprivation. In this paper we report the cloning, sequencing and transcriptional analysis of the genes for cytochrome c-553 and plastocyanin from Anabaena sp. PCC 7120. The gene for cytochrome c-553 encodes a preprotein containing 111 amino acids with a predicted $\mathbf{N}$-terminal transit peptide sequence of $\mathbf{2 5}$ amino acids. The gene for plastocyanin encodes a preprotein containing 139 amino acids with a $\mathbf{N}$-terminal transit peptide sequence of 34 amino acids. RNA transcript analyses indicate that the expression of the genes for cytochrome c-553 (pet/) and plastocyanin (petE) are regulated in reciprocal ways in response to copper concentration. In copper-replete conditions, pet is expressed at very low levels, but is transcribed at high levels under copper deprivation; petE is down-regulated in the absence of copper, but is rapidly up-regulated when copper is added back to the medium.
\end{abstract}

Keywords: Anabaena sp. PCC 7120 , cytochrome $c-553$, plastocyanin, gene regulation, algae, cyanobacteria

\section{INTRODUCTION}

Cytochrome c-553 (c-552) and plastocyanin are soluble photosynthetic electron transporters that ferry electrons between the membrane-bound cytochrome $b_{6}-f$ complex and Photosystem $I$ in cyanobacteria and many eukaryotic algae. Although cytochrome $c-553$ is the only electron carrier performing this function in some cyanobacteria, in others either plastocyanin or cytochrome $c-553$ are used, and their use appears to depend on the availability of environmental copper (Ho \& Krogmann, 1984; Sandmann \& Böger, 1980). Many eukaryotic algae have similar changes in response to copper availability (Sandmann et al., 1983). In the green alga, Chlamydomonas reinbardtii, in vitro translation systems and antibodies to plastocyanin and cytochrome c-552 were used to show that the production of plastocyanin is controlled at the post-

The GenBank accession numbers for the nucleotide sequence data reported in this paper are M97009 and L19417. transcriptional level, while cytochrome $c$-552 expression is controlled at the transcriptional level (Merchant \& Bogorad, 1986). Subsequently, the cloned gene for $C$. reinbardtii cytochrome $c-552$ was used to show that it is only expressed in copper-deficient cells (Merchant \& Bogorad, 1987).

The genes for plastocyanin (petE) and cytochrome $c-553$ (pet $)$ have been cloned from Anabaena sp. PCC 7937 and Synechocystis sp. PCC 6803. Transcript analyses indicated that in Anabaena sp. PCC 7937 petE is strongly downregulated in copper-deficient conditions (Van der Plas et al., 1989); contradictory reports on the expression of pet $E$ in Synechocystis sp. PCC 6803 indicated that the gene is either constitutively expressed under all copper regimes (Briggs et al., 1990) or is regulated in a manner similar to Anabaena sp. PCC 7937 (Zhang et al., 1992). However, in both species pet $J$ was shown to be expressed in the absence of copper and down-regulated when copper was added to the medium (Zhang et al., 1992; Bovy et al., 1992). petJ (called cyt $A$ ) has been cloned in Synechococcus sp. PCC 7942 
and shown to be constitutively expressed under copperreplete and copper-deficient conditions; however, this cyanobacterium does not appear to have a plastocyanin gene (Laudenbach et al., 1990). In this paper we report the cloning and sequencing of pet $J$ and petE from Anabaena sp. PCC 7120 . We demonstrate that pet $J$ shows very low levels of transcription in the presence of environmental copper, but is strongly expressed under conditions of copper deprivation; petE displayed the complementary pattern of transcriptional regulation. Hybridization experiments with total cellular RNA indicate that the message for plastocyanin reaches steady state levels within $1 \mathrm{~h}$ of adding copper to copper-deficient medium.

\section{METHODS}

Materials. All chemicals were reagent grade. Restriction endonucleases were obtained from BRL, New England Biolabs and Pharmacia. Alkaline phosphatase was obtained from Boehringer Mannheim; T4 polynucleotide kinase from New England Biolabs; T4 DNA ligase from BRL. $\left[\alpha_{-}^{32} \mathrm{P}\right] \mathrm{dCTP}$ $\left(3000 \mathrm{Ci} \mathrm{mmol}^{-1}\right)$ was obtained from ICN, and $\left[\gamma_{-}{ }^{32} \mathrm{P}\right]$ ATP $\left(5000 \mathrm{Ci} \mathrm{mmol}^{-1}\right)$ and $\left[{ }^{35} \mathrm{~S}\right] \mathrm{dATP}\left(1000 \mathrm{Ci} \mathrm{mmol}^{-1}\right)$ were obtained from Amersham (1 $\mathrm{Ci}=37 \mathrm{GBq})$.

Culture conditions. Anabaena sp. PCC 7120 was grown in BG11 medium in liquid culture (Allen, 1968) at $29^{\circ} \mathrm{C}$. To prepare copper minus medium, copper was omitted from the micronutrient stock solution of BG11. All media were made in acidwashed glassware with deionized, ultrapure water from a MilliQ Reagent Water System (Millipore).

Library construction and screening. Anabaena sp. PCC 7120 genomic DNA was isolated as follows. Cultured cells were harvested by centrifugation, washed in $50 \mathrm{mM} \mathrm{NET}(50 \mathrm{mM}$ $\mathrm{NaCl}, 50 \mathrm{mM}$ EDTA, $50 \mathrm{mM}$ Tris/ $\mathrm{HCl}, \mathrm{pH} 8.0$ ) and resuspended in $48 \mathrm{ml} 50 \mathrm{mM}$ NET containing $5 \mathrm{mg}$ lysozyme $\mathrm{ml}^{-1}$ per $5 \mathrm{~g}$ wet-packed pellet. The suspension was incubated for $1 \mathrm{~h}$ at $37{ }^{\circ} \mathrm{C}$. After incubation, $6 \mathrm{ml} \mathrm{20 \% (v/v)} \mathrm{Triton} \mathrm{X-100} \mathrm{and}$ $5 \mathrm{ml} 10 \%$ (w/v) Sarkosyl were added; with this mixture of detergent the cells lysed rapidly to form a viscous solution. $\mathrm{NaCl}$ $(5 \mathrm{M})$ was gently mixed in to give a final concentration of $0.4 \mathrm{M}$. The mixture was then sequentially extracted with phenol (saturated with $0.1 \mathrm{M}$ Tris, $\mathrm{pH} \mathrm{8.0)}$ and then with $\mathrm{CHCl}_{3}-$ isoamyl alcohol $(24: 1, \mathrm{v} / \mathrm{v})$ for $15 \mathrm{~min}$ each. Two volumes of ethanol were added and the precipitated DNA was spooled onto a glass rod. The DNA was redissolved in $20 \mathrm{ml}$ TE $(10 \mathrm{mM}$ Tris/ $\mathrm{HCl}, 1 \mathrm{mM}$ EDTA, $\mathrm{pH} 8 \cdot 0$ ), RNase A was added to a final concentration of $40 \mu \mathrm{g} \mathrm{ml}^{-1}$ and the mixture was incubated at $37^{\circ} \mathrm{C}$ for $30 \mathrm{~min}$. The salt concentration was raised to $0.2 \mathrm{M}$ $\mathrm{NaCl}$ by addition of $5 \mathrm{M} \mathrm{NaCl}$. The mixture was carefully extracted once with an equal volume of phenol- $\mathrm{CHCl}_{3}(1: 1$, $\mathrm{v} / \mathrm{v}$ ) and then extracted twice with an equal volume of $\mathrm{CHCl}_{3}$-isoamyl alcohol $(24: 1, \mathrm{v} / \mathrm{v})$. Finally, the DNA was precipitated and spooled as before and dissolved in $15 \mathrm{ml}$ TE. This procedure yielded about $5 \mathrm{mg}$ DNA from an initial $5 \mathrm{~g}$ of cellular pellet.

Partial plasmid libraries were constructed from restrictionenzyme-digested genomic DNA that had been separated by size on a low-melting-temperature agarose gel. Regions of the gel that contained the appropriate fragment size were excised, DNA was isolated from the gel by phenol extraction (Maniatis et al., 1982), and the purified DNA was ligated into restrictionenzyme-digested pGEM-3Zf $(+$ ) (Promega) or pBluescript (Stratagene) for petJ and petE, respectively. DNA transformations of Escherichia coli were performed by the method of
Hanahan (1985), and the libraries were screened by Southern blot hybridization (Southern, 1975) of restriction-enzyme-digested DNA isolated from pooled groups of 25 clones. Finally, individual clones were screened from the group that reacted with the radioactive probes. The probes for pet J are found in Fig. 1; the probe for pet $E$ was a 285 bp PCR fragment generated using oligonucleotides, 5' AAACTAGGCAGCGATAAAGG 3' and $5^{\prime}$ TTTACCGACCATACCAGC 3' from the petE sequence of Anabaena sp. PCC 7937 (Van der Plas et al., 1989). Selected clones were positively identified by double-stranded DNA sequencing and by comparing the translated products of open reading frames with published amino acid sequences of cytochrome c-553 from Anabaena variabilis (Aitken, 1976) and with no.

Amino acid sequence

DNA sequence

Probe I sequence

pet/ sequence

Probe II

Residue no.

Amino acid sequence

DNA sequence

Probe II sequence

pet/ sequence

Probe III

Residue no.

Amino acid sequence

DNA sequence

Probe III sequence

petJ sequence
Probe $\begin{array}{llllllll}52 & 53 & 54 & 55 & 56 & 57 & 58 & 59\end{array}$

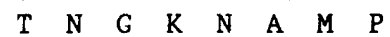

ACNAACGGNAAAAACGCNATGCCN

T $\quad \mathrm{G}$ T

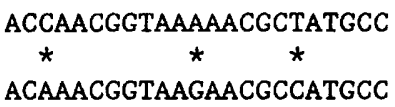

ACCAACGGTAAAAACGCTATGCC

ACAAACGGTAAGAACGCCATGCC

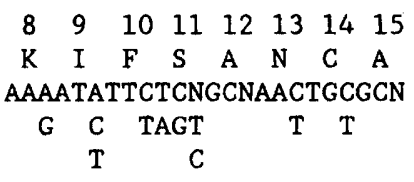

AAAATCTTCTCCGCTAACTGCGC

* T T T

AAGATATTCAGTGCTAACTGCGC $\begin{array}{llllllll}12 & 13 & 14 & 15 & 16 & 17 & 18 & 19\end{array}$

$\begin{array}{llllllll}\text { A } & \text { N } & \text { C } & \text { A } & \text { S } & \text { C } & \text { H } & \text { A }\end{array}$ GCNAACTGCGCNTCNTGCCACGCN

$\mathrm{T} T \underset{\mathrm{T}}{\mathrm{AGC}} \mathrm{T} T$

GCTAACTGCGCTTCCTGCCACGC

$\begin{array}{llll}T & T & T & T\end{array}$

GCTAACTGCGCTTCTTGCCATGC
Fig. 1. Primers used to probe for pet from Anabaena sp. PCC 7120. Three amino acid sequences were selected from conserved areas of cytochrome c-553 from $A$. variabilis. The amino acids are numbered according to Laudenbach et al. (1990). The DNA sequence with staggered bases allows for all the degeneracy of the codons at each position; $\mathrm{N}$ indicates the possibility of having any one of the four bases at that position. The sequence of the probes was arbitrarily selected after consulting the frequency of codon usage from a number of published Anabaena sp. PCC 7120 gene sequences. The actual sequence of petJ for the probe site in Anabaena sp. PCC 7120 (from this report) is placed below the sequence of each probe; asterisks indicate places where the probe differs from the actual sequence. 
ACGATTG

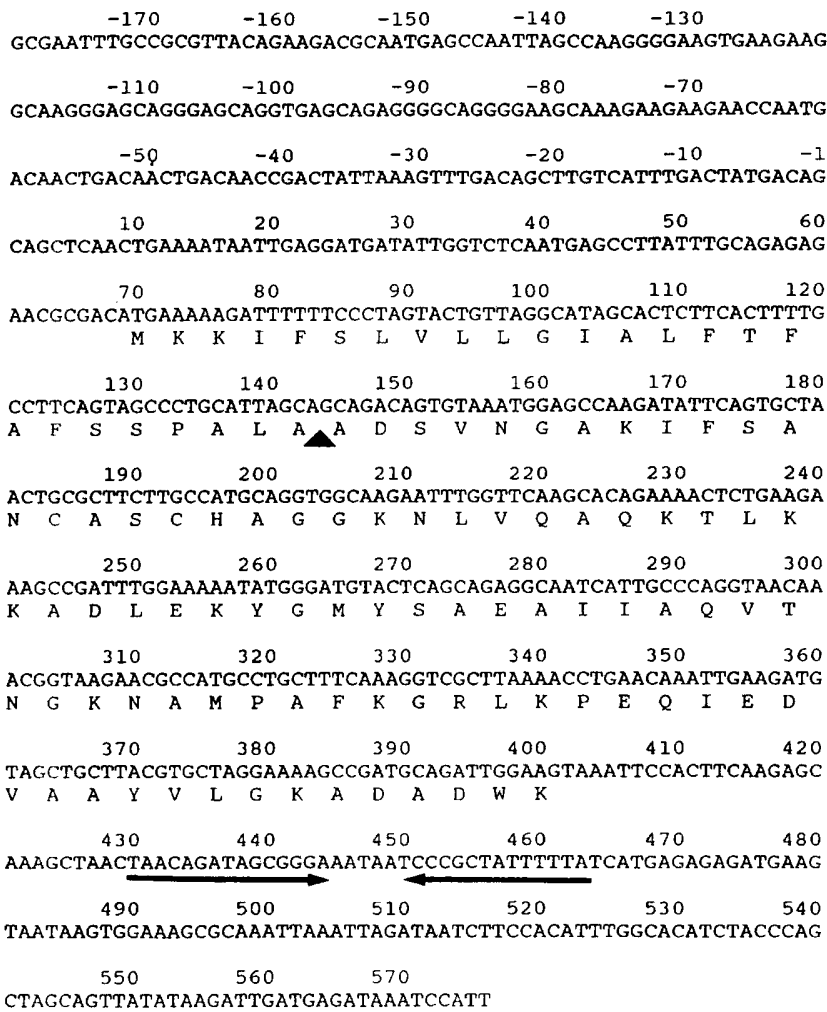

Fig. 2. Nucleotide sequence of pet $J$ and flanking regions. The numbering designates the first transcribed nucleotide as number 1 ; this position was determined by primer extension experiments. The single-letter abbreviations of the deduced amino acid sequence are shown below the nucleotide sequence. A putative transcriptional stop site is underlined with inverted arrows. The putative polypeptide cleavage site is marked with a solid triangle.

published amino acid sequences of plastocyanin from Anabaena sp. PCC 7937 (Van der Plas et al., 1989).

RNA isolation and DNA:RNA blot analysis. Total cellular RNA was isolated by the method of Golden et al. (1987). The RNA was denatured with glyoxal and dimethyl sulphoxide, and electrophoresed on a $1.1 \%(\mathrm{w} / \mathrm{v})$ agarose gel according to Sambrook et al. (1989). RNA from the gel was transferred to nylon membranes (Nytran, Schleicher and Schuell) with the Vacugene transfer system (Pharmacia) and a transfer buffer of $7.5 \mathrm{mM} \mathrm{NaOH}$. DNA:RNA blot hybridizations were carried out at $65^{\circ} \mathrm{C}$ as described by Sambrook et al. (1989). The probes for these hybridizations were PCR fragments that were generated using sequence oligonucleotides that border the open reading frames of pet $E$ and petJ.

Nucleotide sequencing and sequence analysis. Both strands of cloned DNA fragments containing petE or petJ were sequenced by the double-stranded sequencing technique of Zagursky et al. (1985) employing the commercially available Sequenase kit (USB). All sequence reactions were primed by oligonucleotides synthesized on a Cyclone DNA synthesizer (Biosearch). DNA sequence analyses, protein sequence alignments, and protein similarity comparisons were performed with Microgenie version 6.0 (Beckman Instruments).

Primer extension analysis. Primer extension was carried out using the method of Kjems \& Garrett (1988), developed for

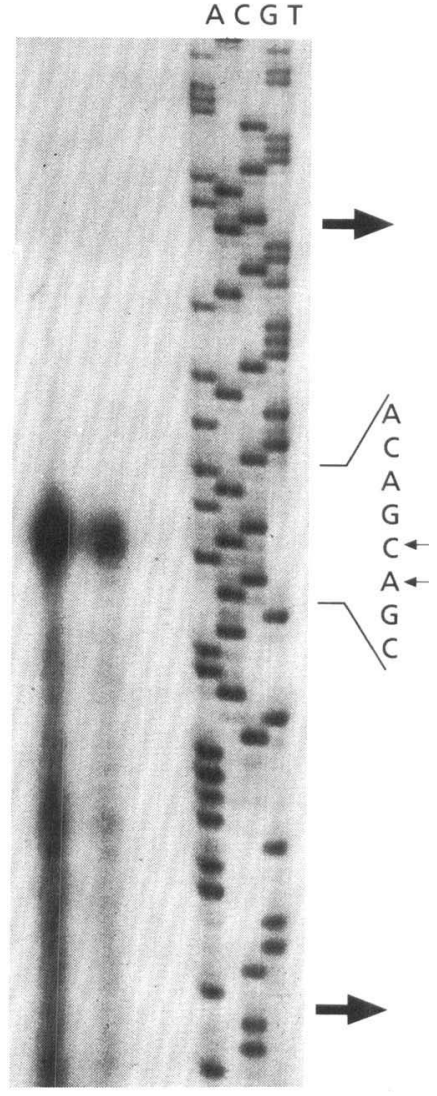

Fig. 3. Transcriptional start site for petJ. The two extension products are marked on the parallel sequence ladder; the arrows indicate the position of the putative transcriptional start sites in the DNA sequence. The sequence ladder was generated using the same oligonucleotide primer (a 24-mer) as that used for primer extension. The lanes of the sequence ladder have been labelled with the bases that complement the dideoxynucleotides of each reaction, so that the sequence read from the ladder corresponds to the sequence of Fig. 2 .

reverse transcriptase sequencing. However, in these reactions the dideoxynucleotides were omitted from the extension mixture, the labelled primer was hybridized overnight to the total RNA, and the extension reaction was carried out at $42{ }^{\circ} \mathrm{C}$.

\section{RESULTS AND DISCUSSION}

\section{Cloning and sequence analysis of pet}

Comparative lists of cytochrome $c-553$ amino acid sequences from eukaryotic algae and cyanobacteria indicate that a significant number of amino acids have been conserved in evolution (Laudenbach et al., 1990; Sprinkle et al., 1986; Aitken, 1976). Two areas that showed a substantial amount of conservation in the cyanobacteria include the haem binding site and the region between residues 50 and 60 (Laudenbach et al., 1990). Fig. 1 contains the sequences of three oligonucleotide probes that were constructed to these two areas. When these probes were hybridized to Southern blots of restrictionenzyme-digested DNA from Anabaena sp. PCC 7120, relatively few bands hybridized to Probe I whereas 


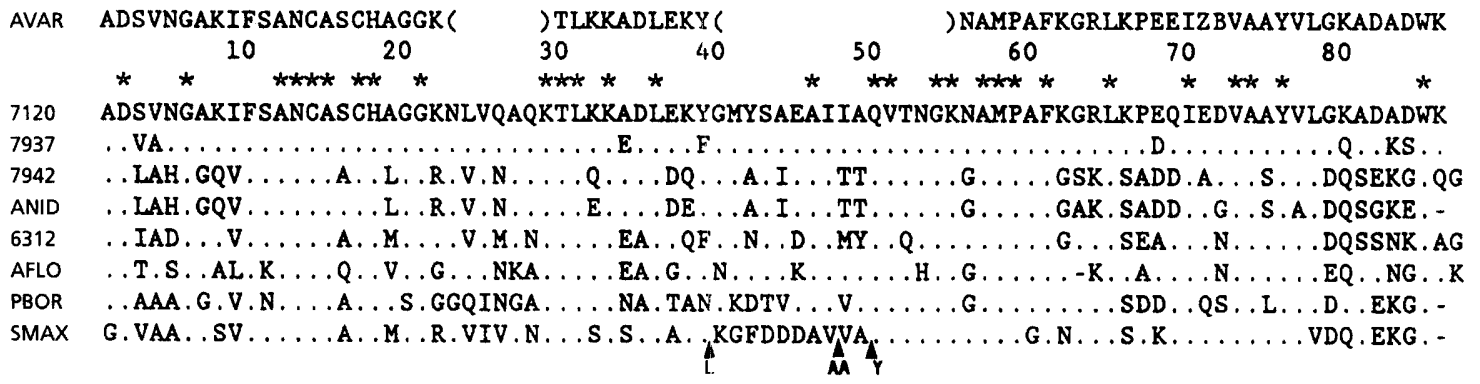

Fig. 4. Comparative alignments of cyanobacterial cytochrome c-553. The alignments were generated by the similarity algorithm resident in Microgenie. The asterisks above the sequences represent the positions of amino acids that are absolutely conserved for all known sequences. Parentheses in the amino acid sequence of $A$. variabilis reflect incomplete sequence in this region. Strains are designated as follows: AVAR, A. variabilis (Aitken, 1976); 7120, Anabaena sp. PCC 7120; 7942, Synechococcus sp. PCC 7942 (Laudenbach et al., 1990); ANID, Anacystis nidulans (Ludwig et al., 1982); 6312, Synechococcus sp. PCC 6312 (Aitken, 1979); AFLO, Aphanizomenon flos-aquae (Ulrich et al., 1982); PBOR, Plectonema boryanum (Aitken, 1979); SMAX, Spirulina maxima (Aitken, 1979). Letters in aligned sequences represent the presence of different amino acids at the position in question; dots indicate that no change has occurred at that position; dashes indicate a postulated deletion; the arrowheads below the sequence of Spirulina maxima indicate the position of inserted amino acids.

multiple bands hybridized to Probes II and III. A series of restriction enzyme fragments were identified which hybridized to all three oligonucleotide probes and to a $0.9 \mathrm{~kb}$ HindIII-PstI fragment of petJ from Synechococcus sp. PCC 7942. Partial plasmid libraries were constructed to these fragments, and DNA from each library was screened sequentially with all four probes. Pooled clones, and subsequently individual clones, were screened with Probe I. Finally, two independent recombinant plasmids were isolated that contained a $2 \cdot 2 \mathrm{~kb} H$ indIII-HincII fragment which hybridized to all the probes. This fragment was shown to contain pet J by double-stranded DNA sequencing using oligonucleotide Probe I as the initial sequencing primer. The sequence of both strands of the entire gene was obtained by double-stranded DNA sequencing using oligonucleotide primers whose sequences were generated from previously run sequencing reactions.

Fig. 2 contains the sequence of the gene for cytochrome c-553 from Anabaena sp. PCC 7120. Primer extension analysis (Fig. 3) yielded two major extension products differing by a single nucleotide; the longest extension product indicated a $5^{\prime}$ leader sequence 68 nucleotides long. The gene encodes a polypeptide of 111 amino acids. On the basis of the published partial amino acid sequence of cytochrome $c$-553 from $A$. variabilis (Aitken, 1976), the mature protein begins at amino acid 26 (alanine) and contains 86 amino acids. The first 25 amino acids form the $\mathrm{N}$-terminal signal sequence required to transport cytochrome $c-553$ across thylakoid and cytoplasmic membranes (Serrano et al., 1990). A potential transcriptional termination structure, with a thermal stability of $\Delta G=-13 \cdot 4 \mathrm{kcal} \mathrm{mol}^{-1}\left(-56 \cdot 0 \mathrm{~kJ} \mathrm{~mol}^{-1}\right)$, is located between nucleotide positions 430 and 463, 28 bases downstream from the last codon of petJ.

Fig. 4 shows a comparison of the amino acid sequence of the mature translated protein of petJ from Anabaena sp. PCC 7120 with the known amino acid sequences of cytochrome $c-553$ from other cyanobacteria. The sequence of the mature protein differs in eight positions from the sequence published for Anabaena sp. PCC 7937 (Bovy et al., 1992). However, our sequence is almost identical to the partial amino acid sequence determined from isolated cytochrome $c-553$ of $A$. variabilis (Aitken, 1976). The two sequences differ in only one amino acid at position 65 where Anabaena sp. PCC 7120 contains a glutamine, whilst $A$. variabilis was reported to have a glutamic acid. The close match between these sequences indicates that these two Anabaena cultures are either the same strain or very closely related strains. Our sequence fills in the two gaps in the sequence from $A$. variabilis, amino acids $19-25$ and $40-55$, and identifies the amino acids at positions 67 and 68 as glutamic acid and aspartic acid, respectively (Fig. 4). Preliminary data citing unpublished results have been reported for these two gaps (Ulrich et al., 1982); our sequence is identical for the first gap (19-25) but differs in 3 of the 16 amino acids in the second gap (40-55, GMYSAEAIIAQVTNGK instead of

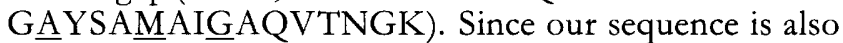
identical to that of Anabaena sp. PCC 7937 in this region it seems reasonable to assume that the preliminary report was in error for these three amino acids.

Alignment of the different mature protein sequences shows a substantial number of strictly conserved sites (Fig. 4). Within these conserved sites are $\mathrm{H}-18$ and M-58 which are the iron ligands, F-61 which is thought to lie near the top of the haem, F-10 and Y-76 which compare to the two aromatic residues forming the right channel in mitochondrial cytochromes $c$ and, of course, C-14 and C17 that covalently bind the porphyrin (Ulrich et al., 1982).

\section{Cloning and sequence analysis of petE}

When hybridized with genomic DNA from Anabaena sp. PCC 7120 , the PCR-generated probe for petE hybridizes with a $2.3 \mathrm{~kb}$ EcoRI-ClaI fragment. Two independently isolated plasmids containing this fragment were isolated from partial plasmid libraries and sequenced (Fig. 5). 


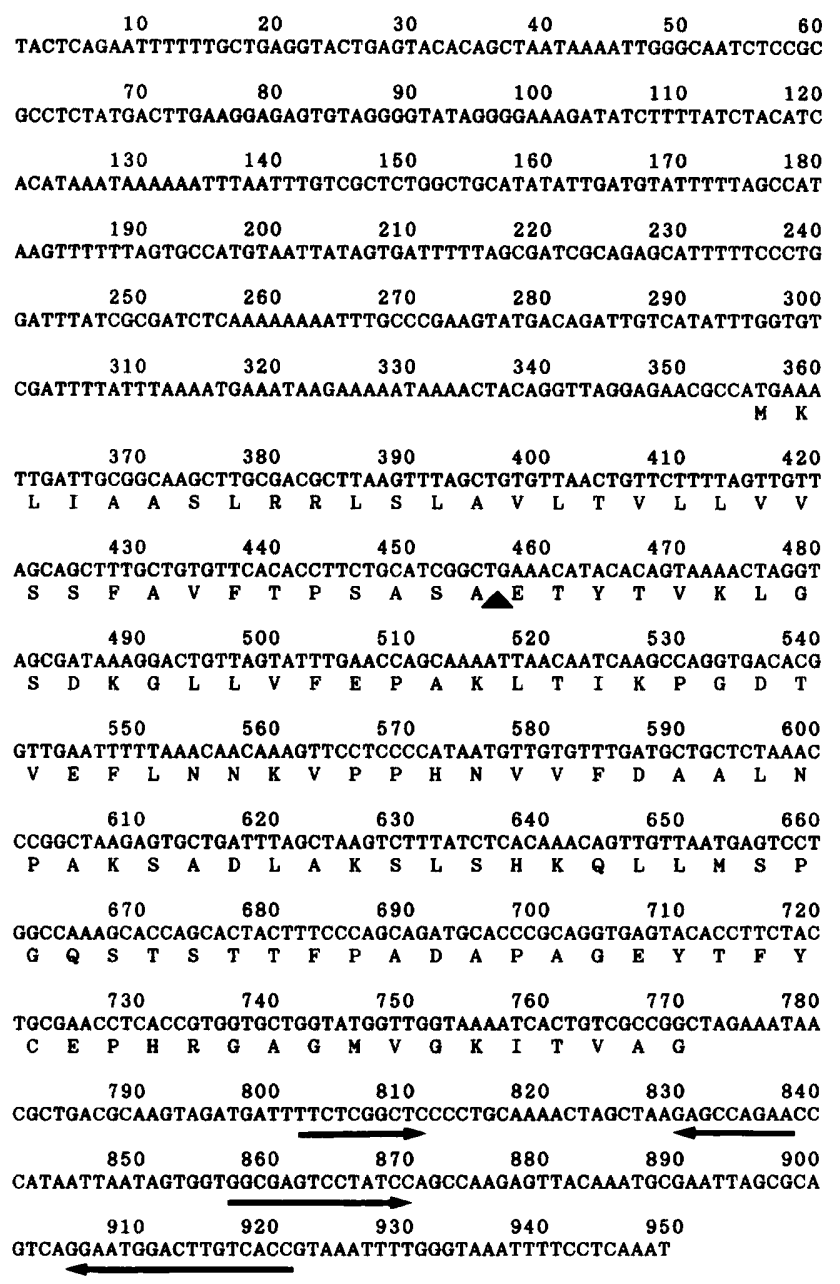

Fig. 5. Nucleotide sequence of petE and flanking regions. The single-letter abbreviations of the deduced amino acid sequence are shown below the nucleotide sequence. Putative transcriptional stop sites are underlined with inverted arrows. The putative polypeptide cleavage site is marked with a solid triangle.

Two potential transcriptional stop structures are located down stream from the last codon of petE; these are nucleotides 802-838 with a thermal stability of $\Delta G=-13 \cdot 2 \mathrm{kcal} \mathrm{mol}^{-1}\left(-55 \cdot 2 \mathrm{~kJ} \mathrm{~mol}^{-1}\right)$ and nucleotides 857-921 with a thermal stability of $\Delta G=$ $-20.2 \mathrm{kcal} \mathrm{mol}^{-1}\left(-84.4 \mathrm{~kJ} \mathrm{~mol}^{-1}\right)$. The open reading frame for pet $E$ encodes a preprotein containing 139 amino acids. By comparing this sequence with that published for Anabaena sp. PCC 7937 (Van der Plas et al., 1989), the preprotein is assumed to have a $\mathrm{N}$-terminal signal sequence containing 34 amino acids and a mature protein sequence of 105 amino acids. Four independent attempts to position the transcriptional start site proved unsuccessful; for these attempts, four different primers were synthesized to hybridize to different locations in the $5^{\prime}$ end of the message (three that were 30 nucleotides long and one that was 24 nucleotides long). Failure to detect an extension product could indicate that the leader sequence contains a stable secondary structure that impedes reverse
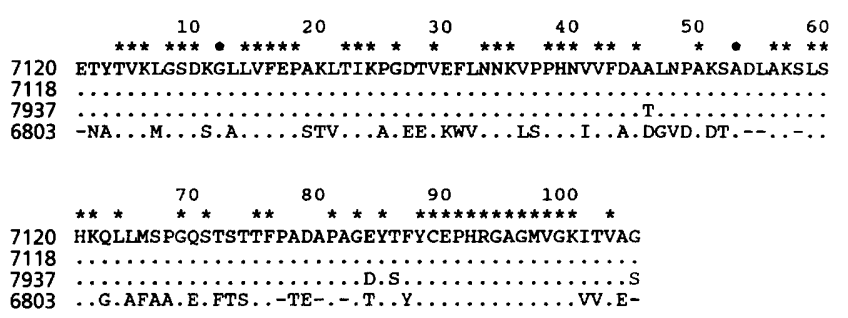

Fig. 6. Comparative alignments of cyanobacterial plastocyanins. 7120, Anabaena sp. PCC 7120; 7118, Anabaena sp. PCC 7118; 7937, Anabaena sp. PCC 7937; 6803, Synechocystis sp. PCC 6803. Letters in aligned sequences represent the presence of different amino acids at the position in question; dots indicate that no change has occurred at that position; dashes indicate a postulated deletion.

transcriptase movement along the message; alternatively, lack of an extension product could result from a message abundance that is too low to produce detectable product. However, since RNA transcript analyses (see Figs 7-9) indicate that the message for pet $E$ is at least as abundant as the message for pet $J$, the former of the two explanations appears to be the more plausible.

In Fig. 6, the sequence of plastocyanin from Anabaena sp. PCC 7120 is compared with plastocyanins from other cyanobacteria. The sequence is identical to that of plastocyanin from Anabaena sp. PCC 7118 (Aitken, 1975), but differs in four positions from the sequence of plastocyanin from Anabaena sp. PCC 7937; only $51 \%$ of the sequence is the same as plastocyanin from Synechocystis sp. PCC 6803.

A comparison of the nucleotide sequences of petE and surrounding regions for Anabaena sp. PCC 7120 and Anabaena sp. PCC 7937 (Van der Plas et al., 1989) indicates that the sequences upstream from the coding region show close homology up to nucleotide position 103 which is 252 nucleotides away from the start codon. After this point, the sequences appear to be totally unrelated. The sudden divergence in sequence homology at this point probably establishes the upper boundary for potential regulatory sequences in the promoter region of this gene. Comparisons of the sequences downstream from the coding region are very similar for the available data. Although a single base difference occurs in the inverted repeated sequences of each of the potential transcriptional termination structures (Fig. 5), the changes do not appear to destabilize either of the structures, since these differences are located in areas of local base mismatching.

\section{$\mathrm{N}$-terminal signal sequences}

On the basis of the reported amino acid sequence for cytochrome $c-553$ from A. variabilis (Aitken, 1976), the first 25 amino acids of the translated open reading frame are not part of the mature protein (Fig. 2). This Nterminal domain of the precytochrome $c-553$ polypeptide has structural characteristics that are similar to those found in prokaryotic signal sequences (von Heijne, 1986; 
Gierasch, 1989). These features include a basic N-terminal region containing two lysines (n-region), a central hydrophobic region (h-region) and a C-terminal region that follows the ' $-3,-1$ rule' (c-region). The c-region of this signal sequence contains alanines in both the -1 and the -3 positions, which is the most frequent configuration for prokaryotic cleavage sites (von Heijne, 1986). The presence of this signal sequence is consistent with evidence that cytochrome $c-553$ in cyanobacteria or its functional equivalent in Rhodobacter sphaeroides is transported into the periplasmic space (Laudenbach et al., 1990; Serrano et al., 1990; Kiley \& Kaplan, 1988). The basic features that characterize $\mathrm{N}$-terminal signal sequences of prokaryotes are also found in the first 34 amino acids of the translated open reading frame of plastocyanin from Anabaena sp. PCC 7120, although this sequence has a substantially longer $\mathrm{n}$-region containing two arginines and one lysine in ten amino acids (Fig. 5). Comparisons between the signal sequences of precytochrome $c-553$ and preplastocyanin show very little relationship, which is surprising because these proteins are thought to be alternative electron donors to P700 (Ho \& Krogmann, 1984) and, thus, would be expected to be targeted to the same region of the cell. However, since signal sequences are notoriously variable (Gierasch, 1989), it would be premature to assume that the differences reported in this paper indicate different targeting sites or even independent transport mechanisms for cytochrome $c-553$ and plastocyanin in Anabaena spp.

\section{Gene copy number}

Some cyanobacteria have been shown to contain a series of closely related genes capable of producing physiologically equivalent proteins for specific functions in photosynthesis. For example three separate loci, $p s b A I$, $p s b A I I$ and $p s b A I I I$, encode the D1 protein and two distinct loci, $p s b D I$ and $p s b D I I$, encode D2 in species of Synechococcus and Synechocystis (Golden et al., 1986; Jansson et al., 1987; Vermaas et al., 1988; Gingrich et al., 1990; Bustos \& Golden, 1991; Kulkarni et al., 1992). Electrophoretically distinct species of cytochromes $c-553$ reported for a number of naturally isolated cyanobacteria indicate that there may be more than one copy of this gene in some cyanobacteria (Ho \& Krogmann, 1984). In Synechococcus sp. PCC 7942 Southern blot hybridization failed to detect more than one copy of pet $J$, and insertional inactivation of this copy produced a mutant with no detectable cytochrome c-553. However, Synecbococcus sp. PCC 7942 does not contain plastocyanin and the single petJ gene is not differentially expressed under different copper regimes (Laudenbach et al., 1990).

To examine whether Anabaena sp. PCC 7120 contains related multiple copies of petJ or petE, total genomic DNA that was digested with a series of different restriction enzymes was reacted with PCR-generated probes for these genes. The Southern blot hybridization at high stringency $\left(65^{\circ} \mathrm{C}, 2 \times \mathrm{SSC}\right.$; not shown) showed that in each case only one fragment reacted to each probe; under these conditions we found that a probe for $p s b D I$ would (a)

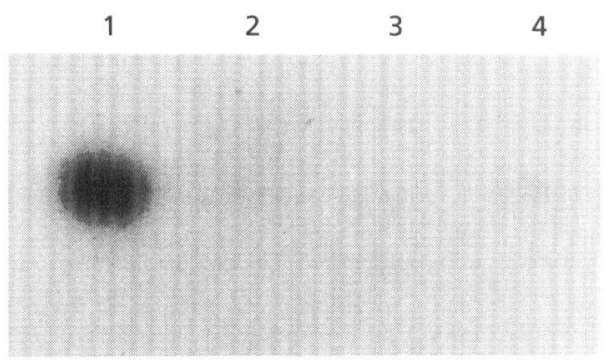

(b)
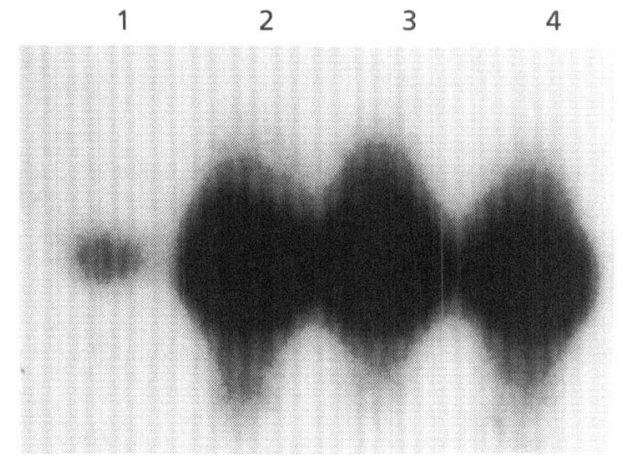

Fig. 7. Transcriptional analysis of petJ and petE. DNA:RNA blot analysis of RNA from cells grown in different copper regimes. (a) Hybridization results for a probe from pet/; (b) results for petE. Lanes 1-4 of each panel represent a sample of $13 \mu \mathrm{g}$ RNA from cells grown in $0,0.3,0.6$ and $0.9 \mu \mathrm{M}$ copper, respectively.

cross-react with DNA fragments from Anabaena sp. PCC 7120 containing $p s b D I I$. This evidence indicates that there is only one copy of petJ or petE per genome in Anabaena sp. PCC 7120.

\section{Transcript analysis of pet $J$ and petE}

To examine how pet $J$ and $p e t E$ are expressed in response to environmental copper concentration, total RNA was extracted from cells grown in normal medium containing different amounts of copper (Fig. 7). These RNAs were reacted by DNA: RNA blot hybridization to radioactive probes for pet $J$ and petE. The patterns of hybridization indicated that the genes are transcribed in a reciprocal manner in response to copper concentration. However, both genes seem to retain low rates of transcription after their expression is down-regulated (this is obvious in Fig. 7 for pet $E$, but requires longer exposure for pet $J$ than shown). The sizes of the transcripts in relation to known single-stranded DNA markers indicate that the message for pet $E$ contains 740 nucleotides and the message for pet $J$ contains 480 nucleotides. The length of the transcript of pet $J$ agrees quite well with the predicted transcriptional start and stop sites of the gene. The predicted lengths also indicate that in each case the messenger RNA is just large enough to accommodate the open reading frames, the $5^{\prime}$ leader sequences and the $3^{\prime}$ trailing sequences of the respective genes. Therefore, both pet $E$ and petJ form 
(a)

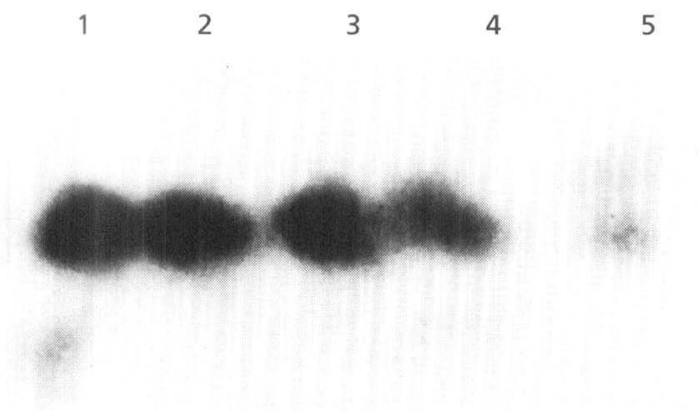

(b)

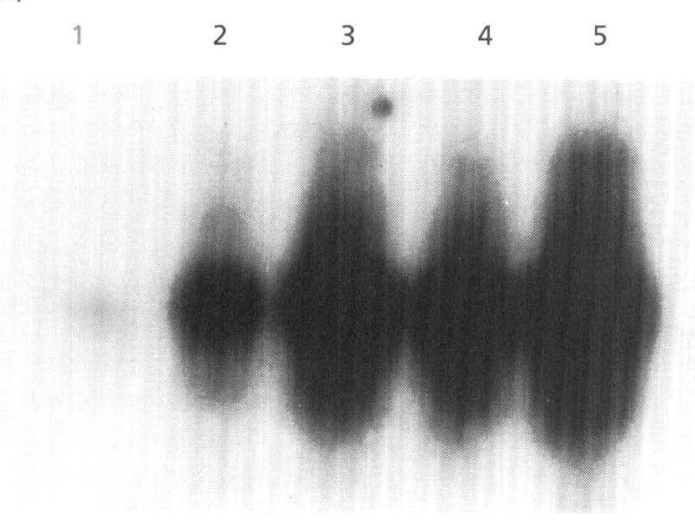

(a)

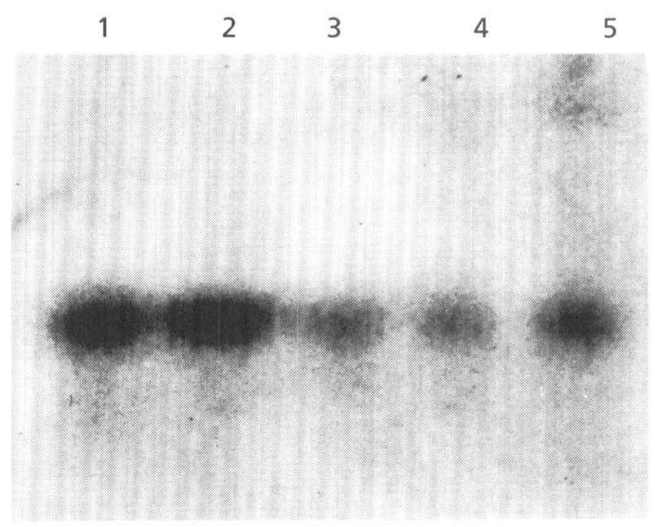

(b)
Fig. 8. Temporal studies of transcriptional response to the addition of copper to the medium. RNA was extracted at different time intervals after the addition of $1.0 \mu \mathrm{M}$ copper to a culture of Anabaena sp. PCC 7120 that was grown in the absence of copper. (a) DNA:RNA blot hybridization results for an $18 \mu \mathrm{g}$ sample of RNA reacted with a probe for pets; (b) results for $12 \mu \mathrm{g}$ RNA reacted with a probe for petE. In (a), lanes 1-5 correspond to times of $0,15,30,60$ and 90 min after the addition of copper, respectively. In (b), lanes 1-5 correspond to times of $0,30,60,90$ and $120 \mathrm{~min}$ after the addition of copper, respectively.

monocistronic operons whose expression is controlled by copper availability.

To examine the temporal aspects of transcriptional regulation, RNA was extracted at different times after the addition of copper to a culture of Anabaena sp. PCC 7120 that was grown in the absence of copper. The DNA: RNA hybridization reactions show that the expression of petE rapidly increased within a period of $30 \mathrm{~min}$ after the addition of copper (Fig. 8). The abundance of RNA from pet $J$ decreased after $30 \mathrm{~min}$, but only showed substantial reduction after $90 \mathrm{~min}$; however, this temporal decrease in message abundance resulted from two factors, the down-regulation of the gene and the stability of the message. To better define the copper concentration responsible for the change in transcription of these two genes, different amounts of copper were added to cultures that were in mid-exponential phase growth in a medium lacking copper. RNA was isolated from each culture $3 \mathrm{~h}$ after the addition of copper and hybridized to each gene

\begin{abstract}
Fig. 9. Transcriptional regulation in response to copper concentration. RNA was extracted $3 \mathrm{~h}$ after the addition of various concentrations of copper to a culture of Anabaena sp. PCC 7120 that was grown in the absence of copper. (a) DNA:RNA blot hybridization results for a probe from pets; (b) results for petE. Lanes 1-5 correspond to added copper concentrations of $0,0.05,0.1,0.4$ and $0.8 \mu \mathrm{M}$, respectively. Each lane represents the reaction of $15 \mu \mathrm{g}$ total cellular RNA.
\end{abstract}

probe. The experiment was designed in this way to avoid changes in copper concentration in the medium that could result from long periods of cellular growth. Fig. 9 shows that the transition in expression of pet $J$ occurred quite sharply between 0.05 and $0.10 \mu \mathrm{M}$ copper; however, the expression of plastocyanin seemed to come on more gradually.

\section{Concluding remarks}

The presence of an alternative electron carrier for plastocyanin in many cyanobacteria and green algae suggests that copper deprivation may be a fairly common environmental phenomenon. Copper deficiency may be a simple result of low abundance of copper in the environment; however, it may also result from secondary effects of iron deprivation. Under the frequently occurring conditions of iron deprivation, bacteria and fungi produce siderophores to scavenge iron from the environment. However, siderophores also bind copper and exclude it from the cell. This enables iron-stressed cyanobacteria to 
grow in environments of copper that would normally be toxic to cellular growth (Boyer et al., 1987). In fact, the copper-siderophore complex appears to be the major copper species present in iron-stressed cyanobacterial blooms (McKnight \& Morel, 1980). Because of this, the relationship between iron stress and copper availability should be re-examined as one of a number of factors that may have led to the loss of plastocyanin from many strains of cyanobacteria (Sandmann, 1986).

However, in other cyanobacteria and many eukaryotic algae, cytochrome $c-553(c-552)$ is an alternative electron donor to P-700, which replaces plastocyanin under conditions of copper deprivation. This report shows that the expressions of both cytochrome c-553 and plastocyanin in Anabaena sp. PCC 7120 are regulated at the transcriptional level, as has been reported for Anabaena sp. PCC 7937 (Bovy et al., 1992), Synechocystis sp. PCC 6803 (Zhang et al., 1992), and for the green alga, Pediastrum boryanum (Nakamura et al., 1992). However, since the expression of petE has also been reported to be constitutive in Synechocystis sp. PCC 6803, it appears that more work is required in this organism to resolve the contradictory evidence (Briggs et al., 1990).

\section{ACKNOWLEDGEMENTS}

This work was supported by a grant to N. A. Straus from the Natural Sciences and Engineering Council of Canada. We would like to thank Junyoung Park for helping in the preparation of this manuscript.

\section{REFERENCES}

Allen, M. (1968). Simple conditions for the growth of unicellular blue-green algae on plates. $J$ Pbycol 4, 1-3.

Aitken, A. (1975). Prokaryotic-eukaryotic relationships and the amino-acid sequence of plastocyanin from Anabaena variabilis. Biochem J 149, 675-683.

Aitken, A. (1976). Protein evolution in cyanobacteria. Nature 263, 793-796.

Aitken, A. (1979). Purification and primary structure of cytochrome c-552 from the cyanobacterium, Synechococcus PCC 6312. Eur J Biochem 101, 297-308.

Bovy, A., De Vrieze, G., Borrias, M. \& Weisbeek, P. (1992). Transcriptional regulation of the plastocyanin and cytochrome $c$ 553 genes from the cyanobacterium Anabaena species PCC 7937. Mol Microbiol 6, 1507-1513.

Boyer, G. L., Gillam, A. H. \& Trick, C. (1987). Iron chelation and uptake. In The Cyanobacteria, pp. 415-436. Edited by P. Fay \& C. Van Baalen. Amsterdam: Elsevier.

Briggs, L. M., Pecoraro, V. L. \& McIntosh, L. (1990). Copperinduced expression, cloning, and regulatory studies of the plastocyanin gene from the cyanobacterium Synechocystis sp. PCC 6803. Plant Mol Biol 15, 633-642.

Bustos, S. A. \& Golden, S. S. (1991). Expression of the $p s b D I I$ gene in Synechococcus sp. strain PCC 7942 requires sequences downstream of the transcription start site. J Bacteriol 173, 7525-7533.

Gierasch, L. M. (1989). Signal sequences. Biochemistry 28, 923-930. Gingrich, J. C., Gasparich, G. E., Sauer, K. \& Bryant, D. A. (1990). Nucleotide sequence and expression of the two genes encoding D2 protein and the single gene encoding the CP43 protein of photosystem II in the cyanobacterium Synechococcus sp. PCC 7002. Photosynth Res 24, 137-150.

Golden, S. S., Brusslan, J. \& Haselkorn, R. (1986). Expression of a family of $p s b A$ genes encoding a photosystem II polypeptide in the cyanobacteria Anacystis nidulans R2. EMBO J 5, 2789-2798.

Golden, S. S., Brusslan, J. \& Haselkorn, R. (1987). Genetic engineering of the cyanobacterial chromosome. Methods Envymol 153, 215-231.

Hanahan, D. (1985). Techniques for transformation of E. coli. In DN A Cloning: A Practical Approach, vol. 1, pp. 109-135. Edited by D. M. Glover. Oxford: IRL Press.

von Heijne, G. (1986). A new method of predicting signal sequence cleavage sites. Nucleic Acids Res 14, 4683-4690.

Ho, K. K. \& Krogmann, D. W. (1984). Electron donors to P700 in cyanobacteria and algae, an instance of unusual genetic variability. Biocbim Biopbys Acta 766, 310-316.

Jansson, C., Debus, R. J., Osiewacz, H. D., Gurevitz, M. \& Mclntosh, L. (1987). Construction of an obligate photoheterotrophic mutant of the cyanobacterium Synechocystis 6803: inactivation of the $p s b A$ gene family. Plant Pbysiol 85, 1021-1025.

Kiley, P. J. \& Kaplan, S. (1988). Molecular genetics of photosynthetic membrane biosynthesis in Rhodobacter sphaeroides. Microbiol Rev 52, 50-69.

Kjems, J. \& Garrett, R. A. (1988). Novel splicing mechanism for the ribosomal RNA intron in the archaebacterium Desulfurococcus mobilis. Cell 54, 693-703.

Kulkarni, R. D., Schaefer, M. R. \& Golden, S. S. (1992). Transcriptional and posttranscriptional components of $p s b A$ response to high light intensity in Synechococcus sp. strain PCC 7942.J Bacteriol 174, 3775-3781.

Laudenbach, D. E., Herbert, S. K., McDowell, C., Fork, D. C., Grossman, A. R. \& Straus, N. A. (1990). Cytochrome $c-553$ is not required for photosynthetic activity in the cyanobacterium Synechococcus. Plant Cell 2, 913-924.

Ludwig, M. L., Pattridge, K. A., Powers, T. B., Dickerson, R. E. \& Takano, T. (1982). Structure analysis of a ferricytochrome $c$ from the cyanobacterium Anacystis nidulans. In Electron Transport and Oxygen Utilization, pp. 27-32. Edited by C. Ho. New York: Elsevier.

McKnight, D. M. \& Morel, F. M. M. (1980). Copper complexation by siderophores from filamentous blue-green algae. Limnol Oceanogr 25, 62-71.

Maniatis, T., Fritsch, E. F. \& Sambrook, J. (1982). Molecular Cloning: a Laboratory Manual. Cold Spring Harbor, NY: Cold Spring Harbor Laboratory.

Merchant, S. \& Bogorad, L. (1986). Regulation by copper of the expression of plastocyanin and cytochrome $c-552$ in Chlamydomonas reinhardtii. Mol Cell Biol 6, 462-469.

Merchant, S. \& Bogorad, L. (1987). The Cu(II)-repressible plastidic cytochrome c. J Biol Chem 262, 9062-9067.

Nakamura, M., Yamagishi, M., Yoshizaki, F. \& Sugimura, Y. (1992). The syntheses of plastocyanin and cytochrome $c-553$ are regulated by copper at the pre-translational level in a green alga, Pediastrum boryanum. J Biochem 111, 219-224.

Sambrook, J., Fritsch, E. F. \& Maniatis, T. (1989). Molecular Cloning: a Laboratory Manual, 2nd edn. Cold Spring Harbor, NY: Cold Spring Harbor Laboratory.

Sandmann, G. (1986). Formation of plastocyanin and cytochrome c553 in different species of blue-green algae. Arch Microbiol 145, 76-79. 
Sandmann, G. \& Böger, P. (1980). Copper-induced exchange of plastocyanin and cytochrome $c-553$ in cultures of Anabaena variabilis and Plectonema boryanum. Plant Cell Lett 17, 417-424.

Sandmann, G., Reck, H., Kessler, E. \& Böger, P. (1983). Distribution of plastocyanin and soluble plastidic cytochrome $c$ in various classes of algae. Arch Microbiol 134, 23-27.

Serrano, A., Giménez, P., Scherer, S. \& Böger, P. (1990). Cellular localization of cytochrome $c_{553}$ in the $\mathrm{N}_{2}$-fixing cyanobacterium Anabaena variabilis. Arch Microbiol 154, 614 618.

Southern, E. M. (1975). Detection of specific sequences among DNA fragments separated by gel electrophoresis. $J$ Mol Biol 98, 503-517.

Sprinkle, J. R., Hermodson, M. \& Krogmann, D. W. (1986). The amino acid sequences of the cytochromes $c_{553}$ from Porphyridium cruentum and Aphanizomenon flos-aquae. Photosynth Res 10, 63-73.

Ulrich, E. L., Krogmann, D. W. \& Markley, J. L. (1982). Structure and heme environment of ferrocytochrome $c-553$ from H NMR studies. J Biol Chem 257, 9356-9364.
Van der Plas, J., Hegeman, H., De Vrieze, G., Tuyl, M., Borrias, M. \& Weisbeek, P. (1989). The gene for the precursor of plastocyanin from the cyanobacterium Anabaena sp. PCC 7937: isolation, sequence and regulation. Mol Microbiol 3, 275-284.

Vermaas, W. F. J., Ikeuchi, M. \& Inoue, Y. (1988). Protein composition of the photosystem II complex in genetically engineered mutants of the cyanobacterium Synechocystis sp. PCC 6803. Photosynth Res 17, 97-113.

Zagursky, R. J., Baumeister, K., Lomax, N. \& Berman, M. L. (1985). Rapid and easy sequencing of large linear double-stranded DNA and supercoiled plasmid DNA. Gene Anal Tech 2, 89-94.

Zhang, L., McSpadden, B., Pakrasi, H. B. \& Whitmarsh, J. (1992). Copper-mediated regulation of cytochrome $c-553$ and plastocyanin in the cyanobacterium Synechocystis 6803. J Biol Chem 267, 1905419059.

Received 6 July 1993; revised 10 November 1993; accepted 24 November 1993. 